\title{
Place Matters: Closing the Gap on Rural Primary Care Quality Improvement Capacity_the Healthy Hearts Northwest Study
}

\author{
Lyle J. Fagnan, MD, Katrina Ramsey, MPH, Caitlin Dickinson, MPH, Tara Kline, MS, \\ and Michael L. Parchman, MD, MPH
}

Context: To compare rural independent and health system primary care practices with urban practices to external practice facilitation support in terms of recruitment, readiness, engagement, retention, and change in quality improvement (QI) capacity and quality metric performance.

Methods: The setting consisted of 135 small or medium-sized primary care practices participating in the Healthy Hearts Northwest quality improvement initiative. The practices were stratified by geography, rural or urban, and by ownership (independent [physician-owned] or system-owned [health/hospital system]). The quality improvement capacity assessment (QICA) survey tool was used to measure QI at baseline and after 12 months of practice facilitation. Changes in 3 clinical quality measures (CQMs) - appropriate aspirin use, blood pressure (BP) control, and tobacco use screening and cessation-were measured at baseline in 2015 and follow-up in 2017.

Results: Rural practices were more likely to enroll in the study, with 1 out of 3.5 rural recruited practices enrolled, compared with 1 out of 7 urban practices enrolled. Rural independent practices had the lowest QI capacity at baseline, making the largest gain in establishing a regular QI process involving cross-functional teams. Rural independent practices made the greatest improvement in meeting the BP control CQM, from $55.5 \%$ to $66.1 \%(P \leq .001)$ and the smoking cessation metric, from 72.3\% to $86.7 \%(P \leq .001)$.

Conclusions: Investing practice facilitation and sustained QI strategies in rural independent practices, where the need is high and resources are low, will yield benefits that outweigh centrally prescribed models. (J Am Board Fam Med 2021;34:753-761.)

Keywords: Ownership, Practice Facilitation, Primary Care Physicians, Primary Health Care, Quality Improvement, Rural Health, Surveys and Questionnaires, Workforce

\section{Introduction}

One out of 5 Americans lives in a rural community ${ }^{1}$ where resources are limited and needs are high. ${ }^{2,3}$ As compared with their urban counterparts, rural

This article was externally peer reviewed.

Submitted 7 January 2021; revised 19 March 2021; accepted 23 March 2021.

From the Oregon Rural Practice-based Research Network, Oregon Health \& Science University, Portland (LJF, KR, CD); Oregon Health \& Science University/Portland State University School of Public Health (KR); Qualis Health/ Comagine Health, Seattle, WA (TK); Kaiser Permanente Washington Health Research Institute, MacColl Center for Health Care Innovation, Seattle, WA (MLP).

Funding: This project is supported by grant numbers R18HS023908 and R18HS023921 from the Agency for Healthcare Research \& Quality (AHRQ).

Conflict of interest: None.

Corresponding author: Lyle J. Fagnan, MD, Oregon Rural Practice-based Research Network (ORPRN), 3181 S.W. residents are generally older, often in poor health, have higher mortality rates for chronic conditions, have decreased life expectancy, and are more likely to experience socioeconomic deprivation and a lack of health insurance. ${ }^{4-8}$ When combined with primary care workforce shortages in rural areas, these factors contribute to the designation of rural residents as a priority population. ${ }^{9}$

Improving the quality of health care in rural settings has been challenging. ${ }^{10}$ Rural primary care practices have difficulties reporting quality measures and implementing quality improvement (QI) initiatives. ${ }^{11}$ In addition to an absence of a QI infrastructure, rural providers report a lack of time and

Sam Jackson Park Road, MC L222, Portland, OR 972393098 (E-mail: fagnanl@ohsu.edu). 
personnel to participate in value-based compensation programs. ${ }^{12,13}$

Over the past 3 decades, ownership and control of rural primary care practices have shifted ${ }^{14,15}$ as physician-owned rural practices have aligned with health systems and regional hospitals. ${ }^{16-18}$ Although the percentage of US physicians who own their practice has been declining at approximately $2 \%$ annually for the past 25 to 30 years, ${ }^{16}$ independent practices continue as a usual source of care for up to fifty percent of people in urban and rural areas. ${ }^{19,20}$ In rural areas, independent practices, often a solo or small practice (2 to 5 providers), ${ }^{21}$ may be the sole source of care for a community. However, the impact of rural status and practice ownership on efforts to support building primary QI capacity and improving clinical quality is not well understood.

Practice facilitation is an effective strategy used to support primary care practices to improve the quality of care..$^{2-24}$ Facilitation is an activity delivered by a facilitator who employs different facilitation skills to enable implementation and improvement. ${ }^{25}$ It is a relationship-oriented activity based on trust and effective communication skills. The remote location and isolation of rural practices suggest that this relationship approach might be especially effective. However, little is known about how primary care practices respond to external practice facilitation based on their rural or urban location and ownership status.

Practice facilitation was the foundational approach for building QI capacity and improving the quality of cardiovascular disease care within small and mediumsized primary care practices in a recent initiative, EvidenceNOW, funded by the Agency for Health care Research and Quality. ${ }^{26,27}$ Healthy Hearts Northwest (H2N), the Pacific Northwest regional cooperatives, enrolled 209 practices across Washington, Oregon, and Idaho. ${ }^{28,29}$ The rural geography of this 3-state region provided a unique opportunity for $\mathrm{H} 2 \mathrm{~N}$ to focus recruitment on rural practices where clinicians might view the project as a priority and as highly relevant to their daily work.

This article compares practices based on both their rural/urban locations and their practice ownership status on how they responded to external practice facilitation support in terms of recruitment, engagement, retention, and changes in their QI capacity and clinical quality metric performance. We hypothesized that rural practices, especially independent practices, when compared with urban practices, will (1) be more likely to participate in the study (recruitment), (2) be more likely to complete the 15 months of offered practice facilitation support (engagement and retention), and (3) demonstrate greater improvements in their QI capacity and performance on the QI measures.

\section{Methods \\ Setting and Subjects}

Study participation required the following eligibility criteria: small or medium size practice (fewer than 10 providers per site); delivery of primary care to adult patients; a location in Oregon, Washington, or Idaho; use of an existing Electronic Health Record (EHR); and a lack significant centralized support for data management and QI. Details on practice recruitment and enrollment have been published elsewhere..$^{28,30}$

This study was determined to be exempt (category 2) by the Kaiser Permanente Washington Health Research Institute's Institutional Review Board, waiving the requirement for informed consent but not ethics review.

\section{Practice Facilitation Intervention}

Briefly, 16 practice facilitators (PFs), each with a cohort of practices to facilitate, provided up to 15 months of active support to each practice. PFs developed a relationship with individuals in the practice to provide a foundation for the QI work, helped develop a $\mathrm{QI}$ team, and worked with them to use their data and feedback to improve performance. ${ }^{28,29}$

\section{Data Collection and Measures}

Data sources for these analyses included (1) data from baseline and follow-up practice and staff surveys; (2) baseline and quarterly clinical performance measurement from each practice on 3 clinical quality measures (CQMs) of cardiovascular disease risk: appropriate aspirin use, blood pressure (BP) control, and smoking cessation support; (3) a quality improvement capacity assessment (QICA) survey used by PFs to guide improvement efforts, and (4) intervention tracking records maintained by PFs, which included counts and types of major disruptions at the clinics.

\section{Practice and Patient Characteristics}

A baseline survey was completed by the office/practice manager in each enrolled practice to collect information about practice characteristics (size, ownership, specialty, clinician-patient panel size, 
staffing) and patient characteristics (insurance status and age groups). Three additional assessments of QI context were assessed with the practice survey: (1) the ability to use data for improvement-customized reports and CQM reports, (2) the degree to which the practice is part of a larger organization with a centralized QI team, and (3) the autonomy of the practice to choose which QI projects suited their focused efforts.

\section{Cardiovascular Risk factor CQMS}

Three different CQMs endorsed by the Centers for Medicare and Medicaid in 2015 were collected from the EHR: appropriate aspirin use (CMS 164), BP control (CMS 165), and tobacco use screening and cessation (CMS 138). ${ }^{31}$ Each CQM was reported as the proportion of the eligible patient population meeting the quality standard. Practices were asked to report CQMs each quarter, using a 12-month rolling lookback period. The data reported here corresponded to clinical care provided for 2015 (the year before the 15-month study intervention) and 2017.

\section{Quality Improvement Capacity}

A validated measure of QI capacity, the QICA, was completed by practice clinicians and staff to measure 7 domains, also called "High Leverage Changes," that contribute to QI capacity: (1) embed clinical evidence; (2) use data to improve performance; (3) establish a regular QI process; (4) identify at-risk patients; (5) define team member roles and responsibilities; (6) improve patient self-management support; and (7) link patients to outside resources. ${ }^{32}$ The 20 -item QICA survey was completed twice during the study, once at the "Kick-Off" in-person meeting in each participating practice with the PF and again during the fourth in-person quarterly visit. The QICA items guided the PFs as they worked with practice QI teams to develop practice-specific changes and engage in Plan-Do-Study-Act cycles of improvement. ${ }^{32}$ Each item was scored between 1 (poor) and 12 (excellent), reaching team consensus on each item score.

\section{Intervention Tracking Records}

Disruptions were defined as major changes in the 12 months before implementation of the QI intervention: implementing a new EHR or billing system, moving to a new location, having clinician turnover, or being purchased by another organization. Baseline disruptions were obtained from the practice survey. The PFs also documented major practice disruptions during their monthly contacts with the practice in the intervention tracking records.

\section{Analysis}

For analysis, we included independently (physicianowned) and health system/hospital-owned primary care practices, excluding 22 Federally Qualified Health Centers and 10 tribal clinics, of which too few were located in rural areas ( $n=5$ and 4 , respectively) to allow for generalizations. We designated independent practices as our reference group. Practices were categorized by rural-urban commuting code (v3.1) and were considered rural if they were category 4 to 10 by zip code and urban if they were category 1 to 3 by zip code. ${ }^{30}$ After testing for differences in retention by location and ownership groups $(P=.83)$, we limited the analysis to the 135 practices completing both a baseline QICA and a second QICA, administered following at least 3 quarters of practice facilitation.

Descriptive statistics are presented as number and percent for categorical variables, mean and standard deviation (SD) for continuous variables with approximately symmetric distributions, and median with the $25^{\text {th }}$ and $75^{\text {th }}$ percentiles for continuous variables with skewed distributions. Group differences for baseline characteristics were tested using $\mathrm{c}^{2}$ tests for categorical variables and the nonparametric KruskalWallis test for ordinal, continuous, or count variables. Changes in the QICA and CQMs were estimated using mixed-effects linear regression models with the 4-level rural/urban independent/systemowned categorical variable, an indicator for baseline vs follow-up measures, and an interaction between the 2. The interaction allowed different rates of change among the types of practices. These models included a random intercept for practice to reflect the correlation between baseline and follow-up measures. While most outcomes were approximately normally distributed, we used robust (empirical) variance estimators to compensate for slight departures from normality. After fitting each regression model, we used the regression coefficients to calculate the mean changes and confidence intervals. For changes, a confidence interval entirely above or below zero (ie, no change) is roughly equivalent to a $P$ value $<.05$. This approach, compared with performing regression on the calculated change scores, allowed us to use all available data, including some from practices missing clinical quality measures at either baseline or followup (approximately $15 \%$ of aspirin and smoking 
observations and $2 \%$ of BP). Compared with a complete case analysis (not shown), this influenced estimates somewhat toward the null.

Analyses were completed using Stata/IC version 15 for Windows ${ }^{33}$ and made extensive use of the user-contributed tabcount command. ${ }^{34}$

\section{Results}

Practice ownership is linked to geography, with health system practices representing $63 \%$ of rural practices and independent practices making up 68\% of urban practices (Table 1). Family medicine is the dominate specialty across all categories (74\%), ranging from $71 \%$ of rural health system practices to $80 \%$ of independent rural practices. Independent practices, in both urban and rural settings, lack central QI resources, reporting high levels of autonomy. Two or more disruptions are more common in rural settings ( $75 \%$ independent, $71 \%$ health system) than urban settings (44\% independent, $46 \%$ health system). The total QICA score averaged 6.4 across practices, with a range of 6.0 for rural independent practices to 6.7 for urban health system practices.

\section{Practice Recruitment and Retention}

A previously published study reported on practice recruitment across 2 of the 7 EvidenceNOW cooperatives (Pacific Northwest, Midwest). ${ }^{30}$ The Pacific Northwest Cooperative (H2N) connected with 1388 practices successfully enrolling 258 practices. The $\mathrm{H} 2 \mathrm{~N}$ dataset showed that $30 \%$ of the recruited practices were rural, and $46 \%$ of the enrolled practices were rural. Rural practices were more likely to enroll in the study, with 1 out of 3.5 rural recruited practices enrolled compared with 1 out of 7 urban practices enrolling $(P \leq .0001)$. The dropout rate was $26 \%$ for rural practices compared with $27 \%$ for urban practices $(P=.87)$. Ownership played a role in dropout rates. Within the health system practices, the rural dropout rate was $23.6 \%$, compared with an urban dropout rate of $26.7 \%$. Within the independent practice groups, the rural dropout rate was $15.4 \%$ compared with an urban dropout rate of $23 \%(P=.66$ for location/ownership interaction).

\section{Practice Engagement}

During the 15 -month $\mathrm{H} 2 \mathrm{~N}$ intervention, all practices received a mean (SD) of 8.7 (2.8) in-person visits lasting a minimum of 30 minutes. The number of visits did not differ by practice location or ownership type, ranging from 8.0 (2.9) for rural independent practices to 9.0 (3.0) for urban independent practices $(P=.57){ }^{28}$

Rural practices tended to have the lowest scores at baseline across all QI capacity domains and their composite score than urban practices (Figure 1). Although all practices improved their overall QICA score, the improvements seen by rural practices, either independent or health system practices, did not differ significantly from their urban counterparts. However, rural independent practices demonstrated notable improvement in their scores on the domains of using the established QI process and embedding clinical evidence compared with their counterparts. (See Supplemental Table S1)

Rural independent practices had the lowest performance at baseline on 2 of the 3 CQM measures, $\mathrm{BP}$ control, and appropriate aspirin use. Across all 3 measures, rural independent practices made the largest gains in improving their performance compared with the other 3 groups, with gains of over 10 percentage points on every measure. This improvement was statistically significant for BP control and smoking cessation. Across rural independent practices, BP control improved from $55.5 \%$ of patients with controlled BP to $66.1 \%(P \leq .001)$. The smoking CQM went from $72.3 \%$ of rural independent practices meeting the performance standard at baseline to $86.7 \%(P \leq .001)$ (Table 2$)$.

\section{Practice Disruptions}

The practice facilitator intervention tracker reported that rural practices, both independent and health system practices experienced a higher rate $(75 \%$ and $71 \%$ ) of disruptions compared with urban independent (44\%) and health system (46\%) practices $(P=.028)$. These study findings are consistent with the baseline practice survey results, where almost 4 out of $5(77.9 \%)$ rural practices (independent and health system) reported multiple major disruptions compared with nearly half $(48.6 \%)$ of urban practices.

\section{Discussion}

Compared with rural health systems or urban practices, rural independent practices were more willing to participate, engage with and make changes leading to improvements in QI capacity and clinical performance measures with support from a facilitator. 


\begin{tabular}{|c|c|c|c|c|c|c|c|c|c|}
\hline \multirow[b]{3}{*}{ Characteristics } & \multicolumn{4}{|c|}{ Rural } & \multicolumn{4}{|c|}{ Urban } & \multirow[b]{3}{*}{$P$ value } \\
\hline & \multicolumn{2}{|c|}{$\begin{array}{c}\text { Independent } \\
\quad(\mathrm{N}=20)\end{array}$} & \multicolumn{2}{|c|}{$\begin{array}{c}\text { Health System } \\
(\mathrm{N}=34)\end{array}$} & \multicolumn{2}{|c|}{$\begin{array}{c}\text { Independent } \\
\quad(\mathrm{N}=55)\end{array}$} & \multicolumn{2}{|c|}{$\begin{array}{l}\text { Health System } \\
\quad(\mathrm{N}=26)\end{array}$} & \\
\hline & $\mathbf{n}$ & $\%$ & $\mathbf{n}$ & $\%$ & $\mathbf{n}$ & $\%$ & $\mathbf{n}$ & $\%$ & \\
\hline \multicolumn{10}{|l|}{ Practice size } \\
\hline 1 (solo) & 3 & 15 & 1 & 3 & 18 & 33 & 2 & 8 & .01 \\
\hline 2 to 4 & 12 & 60 & 19 & 56 & 20 & 36 & 14 & 54 & \\
\hline 5 or more & 5 & 25 & 14 & 41 & 17 & 31 & 10 & 38 & \\
\hline Specialty: Family Medicine & 16 & 80 & 24 & 71 & 41 & 75 & 19 & 73 & .9 \\
\hline Clinicians-assigned panels & 16 & 80 & 31 & 91 & 41 & 75 & 25 & 96 & .047 \\
\hline $\begin{array}{l}\text { Panel size (in practices with panels), } \\
\text { median (quartiles) }\end{array}$ & \multicolumn{2}{|c|}{$\begin{array}{c}1175 \\
\text { (494 to } 2000)\end{array}$} & \multicolumn{2}{|c|}{$\begin{array}{c}1000 \\
(600 \text { to } 1171)\end{array}$} & \multicolumn{2}{|c|}{$\begin{array}{c}1550 \\
\text { (675 to } 2478)\end{array}$} & \multicolumn{2}{|c|}{$\begin{array}{c}1000 \\
(676 \text { to } 1466)\end{array}$} & .053 \\
\hline$\%$ Medicaid & 22 & 19 & 24 & 12 & 19 & 26 & 28 & 20 & .011 \\
\hline$\%$ Medicare & 30 & 19 & 30 & 15 & 21 & 17 & 26 & 19 & .049 \\
\hline No central QI support & 15 & 75 & 8 & 24 & 43 & 80 & 5 & 19 & $<.001$ \\
\hline $\begin{array}{l}\text { Complete/a lot of autonomy to choose } \\
\text { QI projects }\end{array}$ & 16 & 80 & 23 & 68 & 49 & 91 & 15 & 58 & .005 \\
\hline \multicolumn{10}{|l|}{$\begin{array}{l}\text { Number of major disruptions during } \\
\text { study period }\end{array}$} \\
\hline 2 or more & 15 & 75 & 24 & 71 & 24 & 44 & 12 & 46 & .028 \\
\hline 1 & 1 & 5 & 5 & 15 & 13 & 24 & 6 & 23 & \\
\hline 0 & 4 & 20 & 5 & 15 & 18 & 33 & 8 & 31 & \\
\hline Ever run nonstandard CQM report & 4 & 20 & 19 & 56 & 15 & 29 & 10 & 40 & .069 \\
\hline $\begin{array}{l}\text { Confident ( } 4 \text { or } 5 \text { out of } 5 \text { ) generating } \\
\text { CQM report }\end{array}$ & 7 & 35 & 10 & 30 & 27 & 53 & 7 & 30 & .12 \\
\hline Baseline QICA,mean (SD) & \multicolumn{2}{|c|}{$6.0(1.8)$} & \multicolumn{2}{|c|}{$6.2(1.0)$} & \multicolumn{2}{|c|}{$6.6(1.5)$} & \multicolumn{2}{|c|}{$6.7(1.4)$} & .21 \\
\hline $\begin{array}{l}\text { Number of in-person visits by practice } \\
\text { facilitation staff, mean (SD) }\end{array}$ & \multicolumn{2}{|c|}{$8.0(2.9)$} & \multicolumn{2}{|c|}{$8.6(2.1)$} & \multicolumn{2}{|c|}{$9.0(3.0)$} & \multicolumn{2}{|c|}{$8.7(3.2)$} & .57 \\
\hline
\end{tabular}

CQM, clinical quality measure; QI, quality improvement; QICA, quality improvement capacity assessment; SD, standard deviation.

${ }^{*}$ Results are represented as number and percentage unless noted otherwise.

Although a few studies have shown rural practices do not perform as well as urban practices, ${ }^{35,36}$ the response of these practices to the external practice facilitation support offered suggests that it may be particularly suited as a strategy to support rural practices, especially those that are independent, leading to improvements in both their QI capacity and their performance on measures of clinical quality. Why might PF be particularly suited to rural practices?

As described by Berta and colleagues, "Facilitation drives a purposeful. . .change that focuses on building trusting relationships and establishing and sharing common goals between the facilitator and those engaged in making the change." ${ }^{23}$ Because the rural setting is characterized by a high need, low resource environment physically isolated from centers of power, this relational and social process of change may be an especially good fit. Leveraging practice and community strengths by investing in relationships is a necessary implementation asset. ${ }^{37}$

At the start of the intervention, rural independent practices were more likely to lack QI process and have limited ability to use data to create quality metrics and deliver population health management. A connection to a centralized QI infrastructure usually did not exist for rural independent practices. These practices also were less likely to report the ability to generate a nonstandard CQM report. This finding may explain why rural independent practices were highly engaged in the support provided by the facilitator for improving QI data collection and management. The finding that independent practices were more likely to submit the first CQM data within the first 90 days is consistent with a recent $\mathrm{H} 2 \mathrm{~N}$ published study finding that practices with central QI support took longer to submit data compared with practices lacking centralized support. ${ }^{38}$ 
Table 2. Clinical Quality Measures Performance from 2015 to $2017(\mathrm{n}=135)$

\begin{tabular}{|c|c|c|c|c|c|c|}
\hline \multirow[b]{2}{*}{ CQM } & & \multirow{2}{*}{$\begin{array}{c}\text { Baseline } \\
\text { Mean (SD) }\end{array}$} & \multirow{2}{*}{$\begin{array}{c}\text { Final } \\
\text { Mean (SD) }\end{array}$} & \multicolumn{3}{|c|}{ Change } \\
\hline & & & & Mean & $95 \%$ CI & $P$ value \\
\hline \multirow[t]{4}{*}{ Blood pressure } & R-I* & $55.5(11.6)$ & $66.1(10.2)$ & 10.6 & $6.2,15.0$ & $<.001$ \\
\hline & R-HS & $61.2(10.0)$ & $63.5(10.1)$ & 2.3 & $-1.9,6.6$ & .29 \\
\hline & U-I $\mathrm{I}^{\ddagger}$ & $65.8(13.0)$ & $64.7(11.3)$ & -0.7 & $-4.3,2.9$ & .71 \\
\hline & U-HS" & $62.4(11.0)$ & $68.5(12.3)$ & 6.1 & $3.6,8.7$ & $<.001$ \\
\hline \multirow[t]{4}{*}{ Aspirin } & R-I & $57.4(20.6)$ & $67.8(14.1)$ & 10.3 & $-1.0,21.6$ & .08 \\
\hline & R-HS & $69.6(9.1)$ & $72.5(10.7)$ & 2.9 & $-1.7,7.4$ & .22 \\
\hline & U-I & $63.7(17.9)$ & $69.6(13.9)$ & 6.0 & $1.2,10.9$ & .015 \\
\hline & U-HS & $76.9(13.9)$ & $76.3(8.5)$ & -1.4 & $-6.9,4.1$ & .62 \\
\hline \multirow[t]{4}{*}{ Smoking } & R-I & $72.3(24.6)$ & $86.7(11.9)$ & 16.4 & $6.9,26.0$ & $<.001$ \\
\hline & R-HS & $81.8(12.7)$ & $84.9(11.1)$ & 4.3 & $-0.1,8.8$ & .054 \\
\hline & U-I & $65.9(28.1)$ & $77.4(24.1)$ & 9.3 & $2.1,16.4$ & .011 \\
\hline & U-HS & $75.0(24.4)$ & $79.7(24.0)$ & 5.1 & $-4.0,14.2$ & .27 \\
\hline
\end{tabular}

CI, confidence interval; CQM, clinical quality measure; R-I, rural independent; R-HS, rural health system; U-I, urban independent; U-HS, urban health system; SD, standard deviation.

${ }^{*}$ R-I includes 20 clinics.

${ }^{\dagger} \mathrm{R}-\mathrm{HS}$ includes 34 clinics.

${ }^{\ddagger} \mathrm{U}$-I includes 55 clinics.

"U-HS includes 26 clinics.

Creating structural change in practice is foundational to creating QI capacity. ${ }^{39}$ We used the QICA to measure structural change. Compared with other practices, rural independent practices excelled at improving their QI processes and embedding evidence into clinical practice. Their self-assessed score in both domains at the end of the intervention was higher than rural health system practices, even though they were lower

Figure 1. Mean Quality Improvement Capacity Assessment (QICA) self-assessment subscores and totals for 135 primary care practices in Healthy Hearts Northwest, by ownership type and rural/urban location. A. Rural practices had the lowest scores at baseline. B. Almost all gains over the course of the year were statistically significant with $95 \%$ confidence intervals (CIs) that did not include zero (vertical dashed line). The group mean changes were not statistically different from each other (CIs overlap).
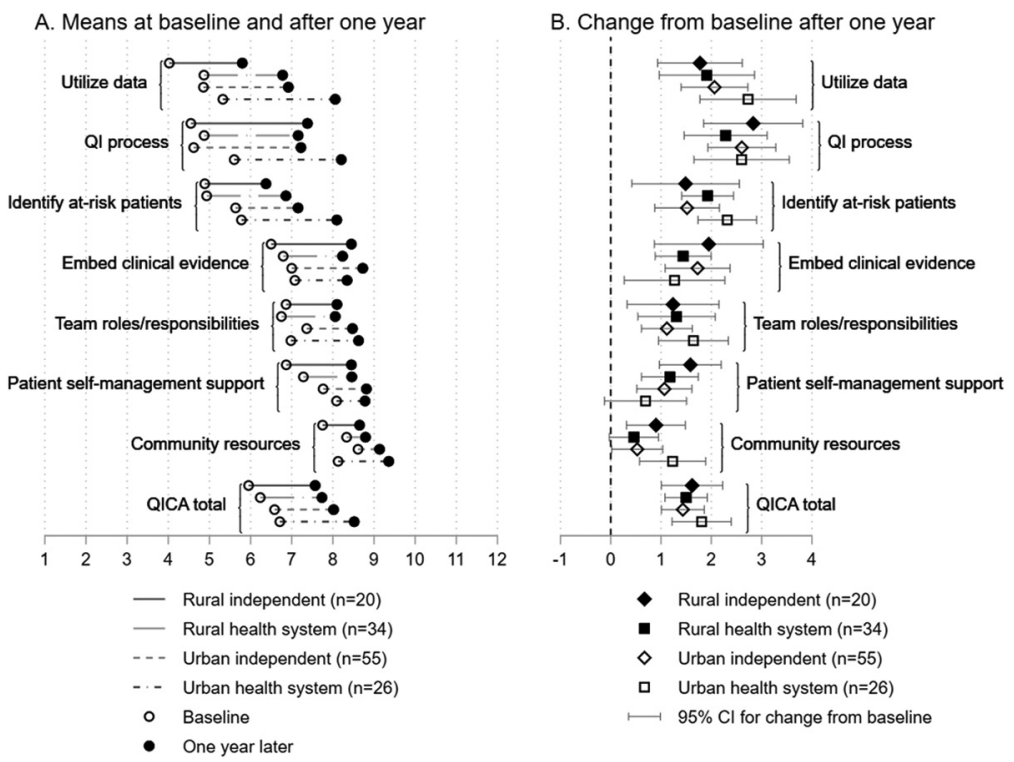
at baseline. Across the 7 HLCs most practice facilitation touches and communications focused on supporting HLC 3: "Establish a regular QI process, involving cross-functional teams." Facilitators reported that these practices generally started from no QI meetings or meetings on an ad hoc basis. Participation in the QI committee was a new experience for many of the practice staff. Using data to understand and improve CQM performance measures (HLC 2) was a challenge for most practices. Rural independent practices, though making improvement, continued to struggle with data management; continued work is needed to develop competency with data management and population health.

Compared with other practices, rural independent practices demonstrated the largest percentage improvement across all 3 CQMs. The BP control CQM showed significant improvement $(P \leq .001)$, closing the gap with urban practices and outperforming rural health system practices. ${ }^{41}$ These changes are even more remarkable considering that major disruptions were more common in rural practices both at baseline and throughout the study intervention. Their ability to make such large improvements in performance on all 3 CQMs despite this high rate of disruptions suggests that these practices have a high degree of resiliency.

Several limitations are to be noted. No control group of practices was available. We are only able to report on outcomes among practices that received external practice facilitation support. However, the purpose of the study was not to test the effectiveness of $\mathrm{PF}$, rather compare the relative effectiveness of PF across practice location and ownership status. The number of practices, primarily rural independent practices, is relatively small and from 1 geographic region of the United States. We were unable to fully explain the impact of health system ownership on the ability of rural practices to improve. We can only state that these findings suggest that rural health system practices were less likely to make the gains in QI capacity and performance than those observed in rural independent practices. The impact of health system ownership on the ability of a primary care practice to innovate and make changes necessary to improve quality requires additional study.

\section{Implications for Improving Rural Primary Care}

The findings of this study suggest rural health system practices are less likely to improve QI capacity and performance on quality metrics compared with rural independent practices with support from a practice facilitator. Practice facilitators are viewed as trusted practice allies who understands that practice context is critical to implementing health delivery transformation and that QI projects as " 1 -size" interventions do not often fit. Frameworks for dissemination and implementation of evidence-based practice improvements have emphasized the importance of adapting and tailoring interventions to the practice context. ${ }^{37,40-45}$ A recent article on medical home functionality and quality suggests tailored technical assistance facilitates primary care transformation. ${ }^{46}$ Practice facilitation as an implementation strategy is uniquely capable of this type of tailoring approach to supporting improvement.

It has been suggested the shift away from rural independent practices is driven more by market and business considerations than a motivation to improve the quality of care in rural areas. ${ }^{47} \mathrm{It}$ is unusual to find a new independent practice in a rural community. Graduates of family medicine residencies do not see independent practice as a viable option, with $89.7 \%$ of graduates seeking an employed position as opposed to $5.7 \%$ pursuing practice ownership. $^{48}$ As a result, existing physician-owned practices struggle to recruit physicians, especially as older physicians retire or leave the practice. ${ }^{49}$ The loss of these independent practices may have an adverse impact on our ability to improve the quality of care in rural communities. If these practices exist in the future, providing them with support from a practice facilitation program may be needed to improve their viability.

In conclusion, findings from this study indicate that for rural practices, especially independent practices, practice facilitation is an especially effective strategy for building QI capacity and improving the quality of care they provide to their rural community. In addition, these data suggest that primary care practices, regardless of location and ownership, may benefit from additional QI facilitation. ${ }^{27}$ This recognition led to the inclusion of the Primary Care Extension Program in the Affordable Care Act passed in 2010; however, no funding for this program was provided. ${ }^{50}$ If we are to ensure highquality equitable care for everyone, regardless of where they live, this issue may need to be revisited.

The authors are grateful to the primary care practices who participated in our study to improve the quality of care to their 
patient populations. The practice facilitators from Qualis/ Comagine Health Oregon Rural Practice Research Network (ORPRN), the research teams at the MaColl Center for Health Care Innovation, Qualis/Comagine Health, and Oregon Health \& Sciences University. The authors gratefully acknowledge the editing and publication assistance from Ms. LeNeva Spires, Portland, Oregon.

To see this article online, please go to: http://jabfm.org/content/ 34/4/753.full.

\section{References}

1. U.S. Census Bureau. One in Five Americans Live in Rural Areas. Washington DC, U.S. Census Bureau; 2017.

2. Kristoff N. Who Killed the Knapp Family? New York Times. January 9, 2020, 2020.

3. Porter E. The Hard Truths of Trying to Save the Rural Economy. New York Times. December 14, 2018, 2018.

4. Gong G, Phillips SG, Hudson C, Curti D, Philips BU. Higher US rural mortality rates linked to socioeconomic status, physician shortages, and lack of health insurance. Health Aff (Hope) 2019;38:2003-2010.

5. Hing E, Burt CW. Characteristics of office-based physicians and their medical practices: United States. Vital Health Stat 13 2005-2006;1-34.

6. James WL. All rural places are not created equal: revisiting the rural mortality penalty in the United States. Am J Public Health 2014;104:2122-2129.

7. Singh GK, Siahpush M. Widening rural-urban disparities in life expectancy, U.S., 1969-2009. Am J Prev Med 2014;46:e19-29.

8. Yaemsiri S, Alfier JM, Moy E, et al. Healthy People 2020: rural areas lag in achieving targets for major causes of death. Health Aff (Hope) 2019;38: 2027-2031.

9. Rak K, Matthews AK, Pena G, et al. Priority populations toolkits: enhancing researcher readiness to work with priority populations. J Clin Transl Sci 2020;4:28-35.

10. Purnell TS, Calhoun EA, Golden SH, et al. Achieving health equity: closing the gaps in health care disparities, interventions, and research. Health Aff (Hope) 2016;35:1410-1415.

11. Cohen DJ, Dorr DA, Knierim K, et al. Primary care practices' abilities and challenges in using electronic health record data for quality improvement. Health Aff (Hope) 2018;37:635-643.

12. Berdahl CT, Easterlin MC, Ryan G, Needleman J, Nuckols TK. Primary care physicians in the MeritBased Incentive Payment System (MIPS): a qualitative investigation of participants' experiences, self-reported practice changes, and suggestions for program administrators. J Gen Intern Med 2019;34:2275-2281.

13. Mendel P. Perspectives of Physicians in Small Rural Practices on the Medicare Quality Payment Program. Santa Monica, CA: RAND Corporation; 2019.
14. O'Hanlon CE, Kranz AM, DeYoreo M, Mahmud A, Damberg CL, Timbie J. Access, quality, and financial performance of rural hospitals following health system affiliation. Health Aff (Hope) 2019; 38:2095-2104.

15. Oyeka O, Ullrich F, Mueller K. Trends in Hospital System Affiliation,. Rural Policy Brief 2018;2018:1-6.

16. Isaacs SL, Jellinek PS, Ray WL. The independent physician-going, going. NEJM 2009;360:655-657.

17. Oyeka O. The Rural Hospital and Health System Affliation Landscape. University of Iowa College of Public Health: RUPRI Center for Rural Health Policy Analysis; November 2018.

18. Wells S, Tamir O, Gray J, Naidoo D, Bekhit M, Goldmann D. Are quality improvement collaboratives effective? A systematic review. BMJ Qual Saf 2018;27:226-40.

19. Cutler DM, Scott Morton F. Hospitals, market share, and consolidation. JAMA 2013;310:1964-70.

20. Mostashari F. The Paradox of Size: How small, independent practices can thrive in value-based care. Ann Fam Med 2016;14:5-7.

21. Liaw WR, Jetty A, Petterson SM, Peterson LE, Bazemore AW. Solo and small practices: a vital, diverse part of primary care. Ann Fam Med 2016;14:8-15.

22. Baskerville NB, Liddy C, Hogg W. Systematic review and meta-analysis of practice facilitation within primary care settings. Ann Fam Med 2012;10:63-74.

23. Berta W, Cranley L, Dearing JW, Dogherty EJ, Squires JE, Estabrooks CA. Why (we think) facilitation works: insights from organizational learning theory. Implement Sci 2015;10:141.

24. Liddy CE, Blazhko V, Dingwall M, Singh J, Hogg WE. Primary care quality improvement from a practice facilitator's perspective. BMC Fam Pract 2014;15:23.

25. Harvey G, Kitson A. PARIHS revisited: from heuristic to integrated framework for the successful implementation of knowledge into practice. Implement Sci 2016;11:33.

26. Meyers D, Miller T, Genevro J, et al. Evidence NOW: balancing primary care implementation and implementation research. Ann Fam Med 2018;16: S5-S11.

27. Sweeney SM, Hemler JR, Baron AN, et al. Dedicated workforce required to support largescale practice improvement. J Am Board Fam Med 2020;33:230-239.

28. Parchman ML, Anderson ML, Dorr DA, et al. A randomized trial of external practice support to improve cardiovascular risk factors in primary care. Ann Fam Med 2019;17:S40-S49.

29. Parchman ML, Fagnan LJ, Dorr DA, et al. Study protocol for "Healthy Hearts Northwest": a 2 × 2 randomized factorial trial to build quality improvement capacity in primary care. Implement Sci 2016;11:138. 
30. Fagnan LJ, Walunas TL, Parchman ML, et al. Engaging primary care practices in studies of improvement: did you budget enough for practice recruitment? Ann Fam Med 2018;16:S72-S79.

31. Centers of Medicare and Medicaid Services. Eligible professional/eligible clinician eCQMs. U.S. Department of Health \& Human Services; 2018.

32. Parchman ML, Anderson ML, Coleman K, et al. Assessing quality improvement capacity in primary care practices. BMC Fam Pract 2019;20:103.

33. Stata Statistical Software: Release 15. StataCorp LLC; 2017.

34. TABCOUNT: Stata module to tabulate frequencies, with zeros explicit. Boston College Department of Economics; 2004. Available from: https://ideas.repec. org/c/boc/bocode/s429501.html. Accessed September 2, 2020.

35. Aarons GA, Hurlburt M, Horwitz SM. Advancing a conceptual model of evidence-based practice implementation in public service sectors. Adm Policy Ment Health 2011;38:4-23.

36. Dotson JA, Roll JM, Packer RR, Lewis JM, McPherson S, Howell D. Urban and rural utilization of evidence-based practices for substance use and mental health disorders. J Rural Health 2014;30:292-299.

37. Louison L. Context Matters-Recommendations for Funders of Program Developers Supporting Implementation in Rural Communities. Chapel Hill, NC: University of North Carolina; April 2017.

38. Parchman MAM, Penfold RB, Kuo E, Dorr DA. The ability of smaller primary care practices to report clinical quality measures: more evidence of size paradox? J Am Board Fam Med 2020;33:

39. Donabedian A. The quality of care. How can it be assessed? JAMA 1988;260:1743-1748.

40. Aarons GA, Green AE, Palinkas LA, et al. Dynamic adaptation process to implement an evidence-based child maltreatment intervention. Implement Sci 2012;7:32.
41. Braithwaite J, Marks D, Taylor N. Harnessing implementation science to improve care quality and patient safety: a systematic review of targeted literature. Int J Qual Health Care 2014;26:321-329.

42. Chambers DA, Glasgow RE, Stange KC. The dynamic sustainability framework: addressing the paradox of sustainment amid ongoing change. Implement Sci 2013;8:117.

43. Miller WL, Rubinstein EB, Howard J, Crabtree BF. Shifting implementation science theory to empower primary care practices. Ann Fam Med 2019;17:250-256.

44. Proctor E, Luke D, Calhoun A, et al. Sustainability of evidence-based healthcare: research agenda, methodological advances, and infrastructure support. Implement Sci 2015;10:88.

45. Wandersman A. Four keys to success (theory, implementation, evaluation, and resource/system support): high hopes and challenges in participation. Am J Community Psychol 2009;43: 3-21.

46. Rittenhouse DR, Wiley JA, Peterson LE, Casalino LP, Phillips RL, Jr. Meaningful use and medical home functionality in primary care practice. Health Aff (Hope) 2020;39:1977-1983.

47. Balasubramanian BA, Marino M, Cohen DJ, et al. Use of quality improvement strategies among small to medium-size US primary care practices. Ann Fam Med 2018;16:S35-S43.

48. Phillips JP, Peterson LE, Fang B, Kovar-Gough I, Phillips RL, Jr. Debt and the emerging physician workforce: the relationship between educational debt and family medicine residents' practice and fellowship intentions. JAMA 2019;94:267-273.

49. Neprash HT, McWilliams JM, Chernew ME. Physician organization and the role of workforce turnover. Ann Intern Med 2020;172:568.

50. Phillips RL, Jr., Kaufman A, Mold JW, et al. The primary care extension program: a catalyst for change. Ann Fam Med 2013;11:173-178. 